\title{
Synthesis of some pyrazole and pyrimidine derivatives of sulfonamides
}

\author{
Rajeev Jain*, Sadhana Shrivastava and Akhilesh Bhadauria \\ School of Studies in Chemistry, Jiwaji University, Gwalior-474 011, India \\ E-mail : gwlsosmica@ sancharnet.in $\quad F a x: 91-751-2346209$
}

Manuscript received 9 January 2003, revised 12 Jamuary 2004, acepted 6 April 2004

\begin{abstract}
1-Carboxymethylpyridinium-3-aminophenyl-5-methyl- $4-\left(f^{\prime}\right.$-sustituted)sulfonamoylazopyrazoles (2a-f) and 2-amino-4-methyl-

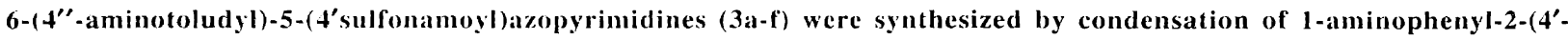
substituted)sulfonamoylhydrazonobutane-1,3-dione (1a-f) with 1-carboxymethylpyridinium-hydrazine chloride (Girard-P) and guanidine nitrate respectively.
\end{abstract}

Chemistry of pyrazoles and pyrimidines has been extensively studied as many drugs include these rings. A number of pyrazole derivatives have been synthesized and found to possess biological activity'. Pyrimidine is widely distributed in living cell and therefore play an important role in many biological processes ${ }^{2}$. Many pyrimidine derivatives exhibit interesting medicinal and biological applications $^{3-5}$. Sulfonamides are well known for their therapeutic value $^{4}$. In light of these facts we have synthesized some new I-carboxymethyl-pyridinium-3-aminophenyl-5-methyl-4'-substituted)sulfonamoylazopyrazoles (2a-f) and 2amino-4-methyl-6-( 4"-aminotoludyl)-5-( 4'-sulfonamoyl) azopyrimidines ( $\mathbf{3 a}-\mathbf{f})$. These compounds were synthesized by diazotisation of sulfonamides.

\section{Experimental}

M. ps. were determined in open capillary tubes and are uncorrected. IR spectra were recorded on a Perkin-Elmer 883 spectrophotometer and ${ }^{1} \mathrm{H}$ NMR spectra (DMSO- $d_{6}$ ) on a Varian spectrophotometer using TMS as an internal standard. Compounds were routinely checked for their purity on silica gel $\mathrm{G}$ plates.

1-Aminophenyl-2-(4'-substituted)sulfonamovl-hydrazonobutane-l,3-diones (1a-f) : Sulfonamide $(0.01 \mathrm{~mol})$ was dissolved in mixture of conc. $\mathrm{HCl}(3 \mathrm{ml})$ and water $(4 \mathrm{ml})$ and cooled to $0^{\circ}$ in an ice bath. To this, cold solution of sodium nitrite $(0.69 \mathrm{~g}, 0.01 \mathrm{~mol})$ was added in small portions with constant stirring. The resulting compound (1a) was filtered and washed repeatedly with water and crystallized from ethanol, $(65 \%)$, m.p. $253^{\circ} ; v_{\max } 3240\left(\mathrm{NH}_{2} \mathrm{O}_{2} \mathrm{~S}\right)$, $3100(\mathrm{ArCH}), 1630(\mathrm{C}=\mathrm{N}), 1660(\mathrm{C}=\mathrm{O}), 1140\left(\mathrm{SO}_{2}\right)$ and $750 \mathrm{~cm}^{-1}$ (substituted phenyl); ${ }^{1} \mathrm{H}$ NMR (DMSO- $d_{6}$ ) $\delta 2.5$ $\left(3 \mathrm{H}, \mathrm{s}, \mathrm{CH}_{3}\right), 7.20-8.10(9 \mathrm{H}, \mathrm{m}, \mathrm{ArH})$ and 13.20 (enolic $\mathrm{OH}$ hydrogen bonded with $\mathrm{C}=\mathrm{O}$ group). Similarly other compounds were prepared (yields 55-65\%) : 1b, m.p. $210^{\circ}$; c, $210^{\circ} ; \mathbf{d}, 232^{\circ} ; \mathbf{e}, 215 ; \mathbf{f}, 242^{\circ}$.

The compound la-f may be exist as :

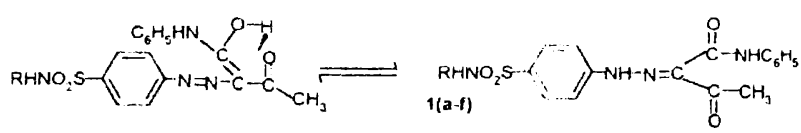

A broad singlet at $\delta 13.20 \mathrm{ppm}$ was observed which is characteristic of hydrogen bonded (chelated) enols. So much deshielding is only possible for chelated enols ${ }^{7}$. The light

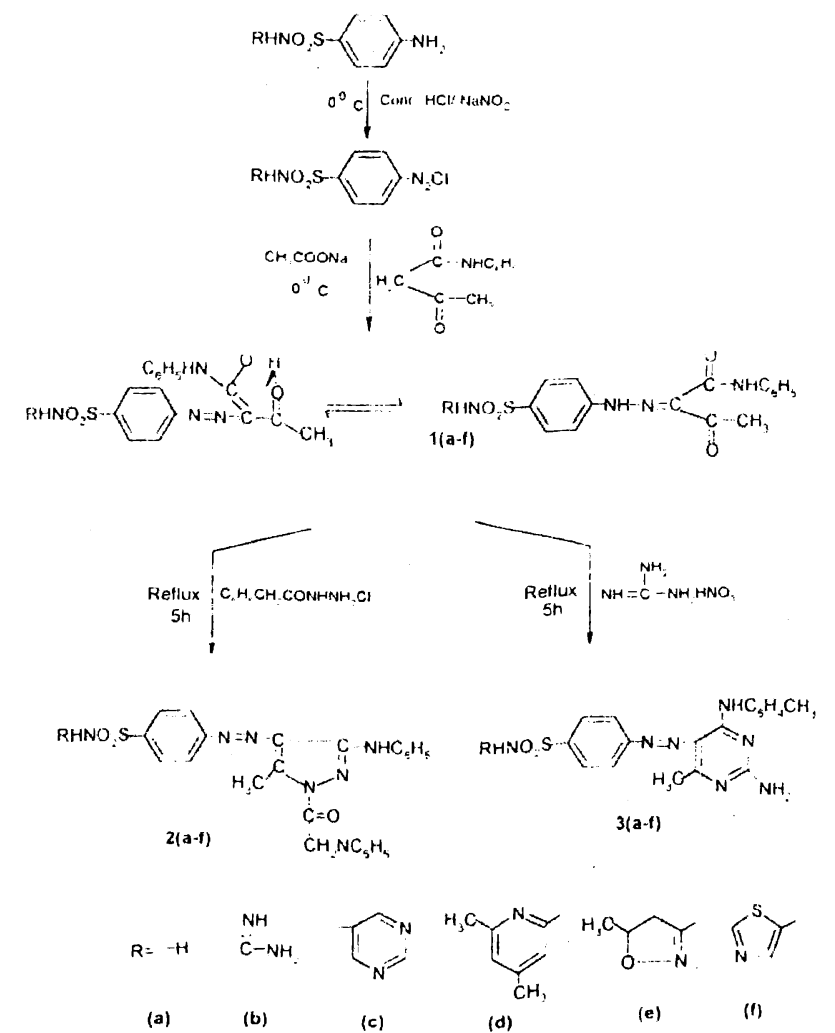


yellow colours of la-f is also indicating the azo functionality in conjugation with benzene ring. The colours of la-f are also comparable with the colour of $\mathbf{2 a - f}$ and $\mathbf{3 a - f}$ which contain the azo $(\mathrm{N}=\mathrm{N})$ group.

1-Carboxymethylpyridinium-3-aminophenyl-5-methyl4-(4'-sufonamoyl)azopyrazoles (2a-j) : A solution of 1 aminophenyl-2-(4'-sulfonamoyl)hydrazonobutane-1,3dione $(1 \mathrm{a} ; 0.001 \mathrm{~mol})$ in acetic acid $(10-15 \mathrm{ml})$ was mixed with Girad-P $(0.001 \mathrm{~mol})$ in acetic acid $(15 \mathrm{ml})$ and the mixture was refluxed for $5 \mathrm{~h}$, then allowed to cool overnight. The resulting solid (2a) was crystallized from ethanol, (65\%), m.p. $189^{\circ} ; \lambda_{\max } 360 \mathrm{~nm} ; v_{\text {max }} 3250\left(\mathrm{NH}_{2} \mathrm{O}_{2} \mathrm{~S}\right), 1140$ $\left(\mathrm{SO}_{2}\right), 1510$ and $1565(\mathrm{C}=\mathrm{N}$ and $\mathrm{N}=\mathrm{N})$ and $1710 \mathrm{~cm}^{-1}$ $(\mathrm{C}=\mathrm{O}) ; \delta 2.4\left(3 \mathrm{H}, \mathrm{s}, \mathrm{CH}_{3}\right), 7.0-7.8(\mathrm{H}, \mathrm{m}$, substituted phenyl), $8.28\left(2 \mathrm{H}, \mathrm{m}, \mathrm{NH}_{2}\right)$. Similarly other compounds were prepared (yields $50-65 \%$ ) : 2 b, m.p. $200^{\circ}$; c, $205^{\circ}$; d, $200^{\circ}$; e, $175^{\circ} ; \mathbf{f}, 178^{\circ}$.

2-Amino-4-methyl-6-(4"-aminotoludyl)-5-(4'-sulfonamoyl)azopyrimidines (3a-f) : An alcoholic solution of l-aminophenyl-2-(4'-sulfonamoyl)hydrazonobutane-1,3dione $(1 \mathbf{a} ; 0.004 \mathrm{~mol})$ was added to a solution of guanidine nitrate $(0.004 \mathrm{~mol})$ in a methanolic $10 \mathrm{~N} \mathrm{NaOH}(10 \mathrm{ml})$. The mixture was refluxed for $5 \mathrm{~h}$ and then left overnight. Solid product thus separated out was washed with metha- nol and hot water. The resulting solid (3a) was crystallized from DMF-ethanol mixture, $(65 \%)$, m.p. $200^{\circ} ; \lambda_{\max } 346.0$ $\mathrm{nm} ; v_{\max } 3320\left(\mathrm{NH}_{2}\right), 1610(\mathrm{~N}=\mathrm{N}), 1160(\mathrm{C}=\mathrm{N}$ or $\mathrm{C}=\mathrm{C})$, $1135\left(\mathrm{SO}_{2}\right), 750 \mathrm{~cm}^{-1}$ (substituted phenyl); $\delta 2.48(6 \mathrm{H}, \mathrm{s}$, $\left.\mathrm{CH}_{3}\right), 3.88\left(2 \mathrm{H}, \mathrm{s}, \mathrm{NH}_{2}\right)$ and $7.2-7.9(4 \mathrm{H}, \mathrm{m}$, substituted phenyl). Similarly other compounds were prepared (yields 55-65\%) : 3b, m.p. $242^{\circ} ; \mathbf{c}, 225^{\circ}$; d, $187^{\circ}$; e, $185^{\circ} ; \mathbf{f}, 215^{\circ}$.

\section{References}

1. Rajeev Jain and Seema Gupta. J. Heterocycl. Chem., 1996, 6, 71; Sankyo Co. Ltd. Jap. Pat. 1983, 58. 124; (Chem. Abstr. 1983. 99. 158416).

2. N. H. Eshab, Alex. J. Pharm. Sci., 1995, 9, 31: M. Koos and K. Novortnaz, Chem. Papers, 1994, 48, 278: A. Stadler and C. O. Kappe, J. Chem., Soc., Perkin Trans. 2, 2000, 150; H. A. Etman, E. G. Sadek and M. A. Metwally, J. Indian Chem. Soc., 1990, 67, 213 .

3. M. G. Assy, J. Inclian Chem. Soc., 1997, 74, 158.

4. S. Kothari, M. Singhal, D. Vijayvergia. R. Vyas and B. L. Verma, J. Indian Chem. Soc., 2000, 77, 329.

5. M. K. Jani. N. K. Undavia and P. B. Trivedi, J. Indian Chem. Soc., 1990, 67, 485 .

6. Rajeev Jain and Jyoti Bhadauria. J. Indiun Chem. Soc., 1997. 74, 643.

7. S. K. Joshi et al.J. Inorg. Nucl. Chem., 1977. 39. 803. 